\title{
Para além do giro linguístico: uma abordagem existencialista da obra de Hayden White
}

Beyond the Linguistic Turn: an Existentialist Approach to Hayden White's Work

PAUL, Herman. Hayden White: The Historical Imagination. Cambridge; Malden: Polity Press, 2011, 204 p.

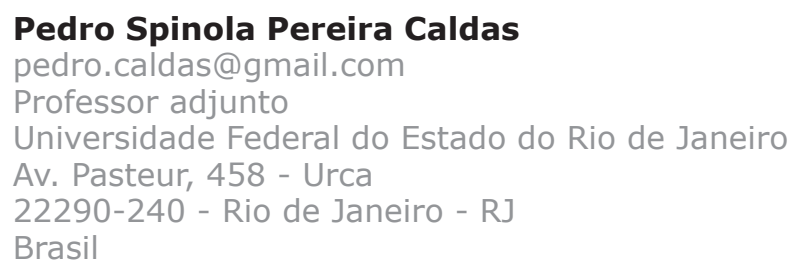

Palavras-chave

Hayden White; Ética; Narrativa.

272 Keywords

Hayden White; Ethics; Narrative. 
É pouco usual um livro ser capaz de aprofundar um tema considerado por muitos já suficientemente discutido e até mesmo esgotado e, ainda por cima, fazê-lo com uma linguagem acessível. É justamente o caso de Hayden White: The Historical Imagination, de Herman Paul (1978-).

Uma reelaboração de sua tese de doutorado, defendida em 2006 na Universidade de Groeningen, na Holanda, e na qual Paul identificava no existencialismo um sólido pressuposto para a interpretação de toda a obra de White, o livro é, porém, mais do que um comentário especializado extremamente sagaz e bem feito - embora também possa ser lido dessa forma. Quem ler o impressionante artigo de Herman Paul publicado no mais recente dossiê da revista History and Theory verá que a preocupação com a importância da ética para a produção metódica do conhecimento histórico não se reduz aos seus estudos sobre Hayden White. Nesse texto (PAUL 2011), o autor demonstra que na obra de historiadores do final do século XIX o conhecimento verdadeiro era inseparável de uma postura moral decidida, na qual o distanciamento de si mesmo e a contenção seriam valores sem os quais o conhecimento histórico seria insustentável.

Esse interesse do autor talvez seja a principal razão pela qual ele não tenha, nem de longe, a pretensão de fornecer uma interpretação definitiva (o que seria até uma contradição nos termos) da obra de Hayden White. Nesse sentido, o livro resenhado aqui é uma introdução (e não uma conclusão) de altíssimo nível, pois apresenta as principais questões que perpassam a obra de White ao invés de tratá-lo como uma estátua inacessível e impenetrável da qual o autor se apresentaria como fiel guardião; ao invés de adotar essa postura, apresenta White como um autor capaz de provocar reflexões não somente sobre teoria da história e história da historiografia, mas sobre as humanidades. E isso merece uma acolhida das mais generosas, sobretudo quando se trata da análise de um autor cujos perfis facilmente se apresentam como esboços de caricaturas.

Herman Paul vai além da "reputação" de White como "narrativista", ainda que sua obra, por ser ensaística, tematicamente eclética e multifacetada (PAUL 2011 , p. 6-7), de fato ofereça dificuldades para aquele que desejar reduzi-la a um campo do conhecimento. De acordo com Paul, a pergunta fundamental levantada pela obra de White trataria do "[...] que significa viver em um mundo histórico, orientar-se no presente e como vislumbrar um futuro moralmente responsável" e, assim, como, a partir da ideia do existencialismo humanista, torna-se possível "[...] desafiar a imaginação histórica de seus contemporâneos, partindo de suas visões políticas e morais" (PAUL 2011, p. 11).

A estrutura do livro é cronológica e acompanha o desenvolvimento das questões de $\mathrm{H}$. White. A opção por tal recorte, se aparentemente não apresenta grandes riscos, por outro lado, permite a $\mathrm{H}$. Paul mostrar o quanto é arbitrário e insuficiente começar a falar de White somente a partir da década de 1970 - quando Meta-história é publicado - ou, na melhor das hipóteses, a partir de "O fardo da história", texto publicado na revista History and Theory na década de $1960 .{ }^{1}$ 
A leitura de Herman Paul nos permite ver textos como "O fardo da história" como uma guinada, como um ponto de maturidade capaz de relacionar a tese (não publicada) de doutorado de White sobre o cisma papal de $1130 \mathrm{com}$ seus artigos mais recentes e bastante lidos. Segundo Paul (2011, p. 19-28), a preocupação de um jovem de 27 anos ao tratar de conflitos da Igreja Católica já era existencialista: o interesse pelos valores, entendidos como impulso para a ação histórica, levou White, desde cedo, a definir o conceito de ideologia para além de uma norma inatingível (como quer Karl Mannheim) ou de uma falsa consciência capaz de levar o homem a "investir na própria infelicidade", para usar os termos de Terry Eagleton. Pelo contrário, para White, a ideologia se estruturaria como um conjunto de valores que induz o homem à ação - e aqui já se sente a importância de Max Weber nos anos de formação de Hayden White.

Mas não seria somente como fonte de ferramentas metodológicas que Weber seria decisivo para o futuro autor de Meta-história. De fato, estava já em desenvolvimento um tema que estaria presente, segundo Paul, em toda a trajetória de White: o compromisso moral. É importante compreender cuidadosamente esse sentido moral, para que ele não seja reduzido a um dogmatismo mofado e intransigente. Ele, na verdade, adquire direito de existência quando pensado a partir de uma avaliação weberiana de "desencantamento do mundo" no qual a vida humana passa a ser um problema técnico: do mundo esperamos soluções, e não problemas e indagações (PAUL 2011, p. 15). Vista como problema, a vida humana não se deixaria reduzir a fórmulas abstratas e metafísicas. Por outro lado e já embebido em existencialismo, White, ao retornar à Itália na década de 1960, passaria a admirar a obra de Benedetto Croce (autor a quem dedicaria parte de Meta-história) e sua noção de que caberia ao indivíduo tentar, por conta própria, repensar o seu passado e criar o seu futuro, ao invés de se deixar seduzir por políticas redentoras (PAUL 2011, p. 31). Graças a Croce, portanto, White, simpático à crítica marxista da sociedade capitalista, rejeita sua solução como filosofia da história (PAUL 2011, p. 29-32).

É neste momento do livro que uma espécie de genealogia do pensamento de White se justifica plenamente, na medida em que Herman Paul oferece uma resposta para o debate entre Dirk A. Moses e o próprio White, impresso nas páginas da revista History and Theory em um fórum publicado em 2005 e no qual Moses propõe uma alternativa weberiana às consequências políticas de White. A indução à clareza, segundo Moses (2005, p. 328), seria preferencial à questão que White gostaria de ver sempre presente no texto do historiador, isto é, "como devemos construir um futuro melhor"?

Sim, Paul faz questão de ressaltar as tendências para a esquerda do pensamento de White: mais do que "escolher valores", o fundamental é ver como tal escolha permite "[...] liberar aqueles cujas condições sociais não permitem que se pense ou se aja em seu próprio favor" (PAUL 2011, p. 36), sendo esse o tema do segundo capítulo: a possibilidade de uma "historiografia da libertação" (liberation historiography). 
Teríamos, portanto, que conceder razão a Moses? Seria, antes, necessário perguntar: o que deverá ser libertado? Curiosamente, é tentador pensar que os primeiros laços a serem desatados seriam os que prendem os historiadores em sua zona de conforto. Assim que retorna de sua segunda temporada italiana, White publica dois trabalhos nos quais discute a irrelevância pública dos historiadores do século XX, que, ao contrário de autores como Tocqueville e Michelet, simplesmente teriam deixado de ser "mediadores entre o passado e o futuro" (PAUL 2011, p. 37). A questão de White, segundo Paul, é importante: "o que os historiadores têm a oferecer para ajudar as pessoas a darem sentido à sua passagem pela história?" (PAUL 2011, p. 37). Pouco, sobretudo quando os historiadores, segundo White, ainda acreditariam viver em um século cujo paradigma de ciência seria o de Herbert Spencer (e não o da física quântica pós-Einstein) e cujo modelo de artista seria Walter Scott (e não Virginia Woolf, Joseph Beuys ou Jean-Luc Godard). Novas formas de representação se fariam necessárias, não para se consagrar a arte pela arte, mas para fazer com que as pessoas pudessem dar maior sentido à sua trajetória.

Aqui, creio eu, Herman Paul poderia ter confrontado um pouco mais Hayden White: se a estratégia de White é política, se partir dessa relação entre representação e atribuição de sentido à história de fato for relevante, seria necessário pensar a diferença entre o público do século $X X$ e do século $X X I$, que é razoavelmente distinto da burguesia culta europeia do século XIX. Se, de fato, o historiador passar a se inspirar formalmente em Kafka e Proust, ou em Godard, deverá pressupor que o público a se educar com essas novas maneiras de se situar no tempo dificilmente atingirá a relevância política do público leitor de $A$ democracia na América. Creio que valeria a pena, sem dúvida, refletirmos nas questões levantadas por White, mas adaptando-as a uma realidade de cultura industrial de massa, fortemente marcada pelo audiovisual, ${ }^{2}$ e que deveria saber articular conquistas de vanguarda com uma linguagem igualmente complexa e acessível.

Segundo Paul - e aqui imagino haver uma boa resposta a Dirk Moses -, o caminho de White seria a postura de revolta de um Albert Camus; ou seja, a de um rebelde que se apresentaria como "[...] defensor da humanidade em toda a sua variedade e imperfeição" (PAUL 2011, p. 47). Nesse sentido, "os únicos deuses e pais que o rebelde reconhece são aqueles compromissados [...] com a capacidade dos indivíduos em viver uma vida própria, de acordo com valores escolhidos por eles mesmos" (PAUL 2011, p. 47).

Este é outro ponto destacado e constantemente retomado por Herman Paul, e que deveria ser motivo para debates contínuos: qual o significado dessa "escolha"? Não pode ser, como diz Frank Ankersmit em ensaio bastante interessante, uma opção totalmente livre de determinações e constrangimentos; se, por um lado, como bem lembra Paul em outro artigo sobre White, o convite para uma historiografia humanista significaria "pegar a sua vida com as próprias mãos, sem projetar em um nível transcendental qualquer autoridade ou

\footnotetext{
2 Neste sentido, é interessante, mas talvez ainda sem o aprofundamento necessário, o trabalho de Robert Rosenstone sobre as tentativas de se pensar, com e a partir do cinema, as questões levantadas por Hayden White. Cf. ROSENSTONE 2010.
} 
responsabilidade moral" (PAUL 2009, p. 60), é necessário levar em consideração que esse gesto (de pegar a vida com as próprias mãos) se dá dentro de uma prefiguração (Cf. ANKERSMIT 2009, p. 37-40).

Paul mostrará, ao longo de seu livro, como a tensão da obra de White - e aqui entendo "tensão" justamente como sinônimo de "fecundidade" - reside na relação entre a prefiguração e o ato de narrar. E é nessa chave que, segundo a interpretação de Herman Paul, Meta-história, às vésperas de completar quarenta anos, torna-se uma leitura cada vez mais rica. Aqui o leitor deveria prestar atenção redobrada no terceiro capítulo de Paul: Meta-história é um livro sobre prefigurações e não simplesmente sobre narrativas (PAUL 2011, p. 59). As prefigurações não são meramente estéticas: o que White tenta mostrar é como diferentes formas de realismo historiográfico no século XIX não se distinguiriam exclusivamente pela pertinência empírica das fontes consultadas, mas pelas implicações ideológicas e éticas. E era justamente essa interconexão que dava a historiadores como Tocqueville, Michelet, Carlyle e outros sua relevância pública. Mas o problema, claro, permanece: se é o caso de recuperarmos a vivacidade da historiografia, como fazê-lo se White nos mostra que ela se faz mediante o uso ou a mobilização de estruturas das quais talvez não tenhamos consciência e manejo absolutos? Paul formula muito bem o problema: "Mas como esta nova história poderia ser ensinada se a imaginação humana é sempre limitada pelas modalidades da linguagem poética? Esta última não se tornaria incongruente com a liberdade e criatividade enfatizadas por White?" (PAUL 2011, p. 77). A aposta, 276 claro, não seria em uma liberdade "adolescente", mas em uma "responsabilidade cognitiva" (saber que se é prefigurado) e, sobretudo, na recusa das imposições obscurantistas e dogmáticas, recusa essa que despe o rei e mostra que há mais de uma maneira de se fazer história (PAUL 2011, p. 79-81).

Ainda assim, o problema retorna, quase como um Leitmotiv, no capítulo seguinte ("The Power of Discourse"): "até que ponto uma análise estruturalista da linguagem do historiador era compatível com uma compreensão humanista da individualidade (selfhood) humana?" (PAUL 2011, p. 91). É uma questão que sempre gira em torno da tropologia. Como lembra Richard T. Vann, nomes como Frederic Jameson e Dominick La Capra sempre se perguntaram o quão profundas - digamos, inconscientes - seriam as estruturas tropológicas dos discursos (VANN 1998, p. 150). Mas Paul tenazmente elabora a questão, sugerindo que os autores abordados em Meta-história - como Michelet e Tocqueville - escreviam de forma menos "profissional", decodificada, especializada, e, por isso, mais comunicativa com seu público.

Poderia lembrar que o problema parecerá insolúvel somente para quem partir de uma inconciliável dicotomia entre consciência e inconsciência, estrutura e evento. A questão me parece ser antes dialética, mais precisamente expressa na dialética entre o estranhamento do familiar e a familiarização do estranho - e me parece digno de discussão como podermos pensar em uma orientação da vida prática pode depender de um e de outro. Será que a elaboração dessa dialética, desse pêndulo, não ajudaria a aprofundar as ponderações tão bem levantadas por Paul e, para citar só um caso, Andrew Baird (Cf. BAIRD 2009), 
cujo excelente artigo sobre o significado da ironia em Hayden White nos convida a pensar como se pode agir historicamente sabendo, de antemão, que a estrutura desse conhecimento é essencialmente irônica?

Talvez um caminho possível para pensar o problema - e, assim, talvez contornar tal aporia - resida no questionamento da ênfase na escolha, ou, para ser mais exato, no pragmatismo que não põe em dúvida a questão: "que uso fazer do passado"? Questionamos tanto nossa capacidade subjetiva de compreensão como questionamos a objetividade do passado, mas não questionamos a ideia de usá-lo. E se invertêssemos a pergunta, sem, todavia, sucumbir a um (des) interesse antiquário? E se perguntássemos: o que ocorre quando nos damos conta de sermos assaltados pelo passado, quando o surpreendemos em nós mesmos, antes de nossa escolha de e como usá-lo? Poderíamos continuar a optar pela resposta obscurantista - "prefiro não saber" -, ou, antes, apostaríamos por que o conhecimento está acima das suas consequências práticas imediatas, e, assim, a história se somaria à psicanálise e nos ajudaria a ver que não somos senhores de nossa própria casa?

Pensado dessa forma, creio que podemos escapar da aporia obsessivamente destacada por Herman Paul - um grande mérito de seu livro - e, dessa forma, fugir também da gasta crítica a White de que, posto que tudo poderia ser "escolhido" estética e moralmente, os negacionistas do Holocausto ficariam à vontade para montar seus covardes enredos. Esse é um tema já apresentado no capítulo "Masks of Meaning: Facing the Sublime", cuja preocupação central é a seguinte: "poderia o argumento de White em favor de tal produção de sentido ser sequestrado por pessoas com pouca inclinação humanista?" (PAUL 2011, p. 122).

Creio que Paul nos ajuda bastante a colocar o problema em outros termos, mais precisamente nos termos do conceito de "evento modernista", de White. Esse seria o evento que, por mais que não gere nenhuma forma de identificação, precisa ser reconhecido como uma possibilidade real do mundo contemporâneo.

É na chave do que gostaria de chamar de incontornável engajamento que poderíamos compreender a interpretação de White sobre Maus, de Art Spiegelmann, assim como o destaque dado por Paul à importância da escrita intransitiva - conceito de Roland Barthes. Não se trata de falar simplesmente sobre a escrita, em um processo romântico e narcísico, mas, sim, de articular de forma inseparável o conteúdo da forma. O evento modernista conduz ao engajamento ao mostrar que contar histórias é uma forma de vivê-las.

Para concluir, portanto, fica a indicação da leitura do formidável livro de Herman Paul; é raro encontrar uma introdução que já apresente questões capazes de renovar o debate sobre uma obra indispensável como a de Hayden White.

\section{Referências bibliográficas}

ANKERSMIT, Frank. White's "New Neo-Kantism". In: ; DOMAŃSKA, Ewa; KELLNER, Hans. Re-figuring Hayden White. Stanford: Stanford University Press, 2009. 
BAIRD, Andrew. Metahistory as Anabasis. In: ANKERSMIT, Frank; DOMAŃSKA, Ewa; KELLNER, Hans. Re-figuring Hayden White. Stanford: Stanford University Press, 2009.

MOSES, Dirk. Hayden White, Traumatic Nationalism and the Public Role of History. History and Theory, Middletown, Vol. 44,Outubro 2005.

PAUL, Herman. Hayden White and the Crisis of Historicism. In: ANKERSMIT, Frank; DOMAŃSKA, Ewa; KELLNER, Hans. Re-figuring Hayden White. Stanford: Stanford University Press, 2009.

. Distance and Self-Distanciation: Intellectual Virtue and Historical Method around 1900. History and Theory, Middletown, Vol. 50, no 4, Dezembro 2011.

. Hayden White: The Historical Imagination. Cambridge; Malden: Polity Press, 2011.

ROSENSTONE, Robert A. A História nos filmes, os filmes na história. São Paulo: Paz e Terra, 2010.

VANN, Richard T. The Reception of Hayden White. History and Theory, Middletown, Vol. 37, no 2, 1998. 